Research from the South

\title{
Training doctors and surgeons to meet the surgical needs of Africa
}

\author{
D A K WATTERS, A C BAYLEY
}

\begin{abstract}
An audit of the operations performed and the use of anaesthesia over one year at the University Teaching Hospital, two proviacial hospitals, and five district or church hospitals in Zambia was carried out. The aim of the audit was to determine what proportion of operations required full surgical training and to collect information on which recommendations for training surgeons in central Africa could be based.

Of the 21245 operations performed, $18401(86.4 \%)$ were found not to be complex, and the procedures could be taught to nonsurgeons. General anaesthesia was used often, but if more doctors were trained to give local and regional anaesthesia more necessary surgery could be performed.
\end{abstract}

\section{Introduction}

Existing health services cannot meet the needs of people for operations in developing countries. Nordberg estimated that only $10-15 \%$ of patients who required repair of inguinal hernias or caesarean sections were operated on in east Africa. ${ }^{1}$ Most people in developing countries live in rural areas, but the facilities for performing operations and the surgeons are concentrated in the cities. The results of a study in Colombia, South America, however, suggested that there was underuse of both operating theatres and well trained surgeons in these centres, as well as poor organisation. ${ }^{2}$ Three quarters of operations performed in a large district hospital in Colombia could have been done by doctors who did not have a full surgical training. ${ }^{2}$

Who should be trained and how can the trainee best be prepared to perform the range of operations required in rural Africa? To answer these two questions we carried out a survey of operations

University Teaching flospital, Lusaka, Zambia

D A K WATTERS, CHM, FRCSED, senior lecturer in surgery

A C BAYLEY, OsE, FRCs, associate professor of surgery in four church hospitals, one district hospital, two provincial hospitals, and the University Teaching Hospital in Zambia.

\section{Methods and results}

We examined the operation registers of the hospitals which had been kept by the nurse's. Each operation for 1984 was recorded except for Chitokoloki and Chikankata hospitals, where figures for 1985 were recorded. The numbers at the University Teaching Hospital were so large - 15937 a yearthat the number for six months was recorded and then doubled. The type of anaesthesia used for each operation was also recorded.

The operations were grouped according to the following subspecialties: general surgery, urology, orthopaedics, obstetrics and gynaecology, ophthalmology, and otolaryngology and within each subspecialty according to complexity and the extent of surgical training required. The four categories were:

Group A-Operations that should be within the competence of any qualified doctor or suitably trained paramedic-for example, incision and drainage of abscess, wound repair, insertion of an intercostal drain, removal of a foreign body from the cornea, and catheterisation.

Group $B$-Operations that could be performed by a doctor or paramedic specially trained for the procedure-for example, hernia repair, dilatation and curettage, caesarean section, manipulation of closed fractures, and cataract extraction.

Group $C$-Operations that normally should be performed by someone with a higher qualification and surgical training appropriate for developing countries-for example, hysterectomy, open prostatectomy, cholecystectomy, and internal fixation of fractures.

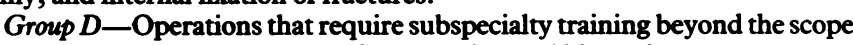
of the average general surgeon-for example, total hip replacement, surgery for glaucoma, repair of vaginal fistulas, sphincter saving coloanal and ileoanal surgery, and transurethral prostatectomy.

Table I gives the number of doctors with surgical and anaesthetic skills at each hospital during the period of the study, as this affects the type and number of operations performed. There were no neurosurgeons or cardiothoracic surgeons in Zambia at this time. One district hospital, Luwingu, had no doctor during the study and therefore only 95 operations were performed (table I), mainly incision and drainage of abscesses and manipulation of simple fractures.

Operations in general surgęry and obstetrics and gynaecology accounted

TABLE I-Details of eight hospitals in central Africa for one year

\begin{tabular}{|c|c|c|c|c|c|c|c|c|}
\hline & $\begin{array}{l}\text { University } \\
\text { Teaching } \\
\text { Hospital }\end{array}$ & Monze & Mongu & Luampa & Solwezi & Chikankata & Chitokoloki & Luwingu \\
\hline $\begin{array}{l}\text { No of admissions } \\
\text { Average No of patients a day } \\
\text { No of beds or cots } \\
\text { No of deliveries } \\
\text { No of caesarean sections } \\
\text { No of major opetations } \\
\text { No of minor operations } \\
\text { No of doctors } \\
\text { No of surgeons (FRCS) } \\
\text { No of anaesthetists } \\
\text { No of clinical officer anaesthetists }\end{array}$ & $\begin{array}{r}92721 \\
1191 \\
1633 \\
23900 \\
767 \\
3953 \\
13691 \\
195 \\
20 \\
4 \\
20\end{array}$ & $\begin{array}{r}12495 \\
918 \\
266 \\
1963 \\
117 \\
136 \\
489 \\
5 \\
0 \\
0 \\
2\end{array}$ & $\begin{array}{r}17808 \\
250 \\
374 \\
1445 \\
48 \\
226 \\
1832 \\
8 \\
2 \\
2 \\
0 \\
2\end{array}$ & $\begin{array}{r}2118 \\
97 \\
141 \\
336 \\
9 \\
228 \\
259 \\
2 \\
0 \\
0 \\
0\end{array}$ & $\begin{array}{r}8128 \\
152 \\
208 \\
637 \\
8 \\
187 \\
361 \\
11 \\
2 \\
1 \\
2\end{array}$ & $\begin{array}{r}5748 \\
222 \\
280 \\
586 \\
57 \\
175 \\
496 \\
3 \\
0 \\
0 \\
1\end{array}$ & $\begin{array}{r}2149 \\
204 \\
254 \\
223 \\
20 \\
242 \\
517 \\
2 \\
0 \\
0 \\
0\end{array}$ & $\begin{array}{r}2283 \\
29 \\
55 \\
156 \\
0 \\
0 \\
95 \\
0 \\
0 \\
0 \\
0\end{array}$ \\
\hline
\end{tabular}

Note: Some figures were obtained from Ministry of Health annual returns. The numbers of operations are not necessarily the same as those obtained from operation registers. 
for over three quarters of those done in all the hospitals. Operations in urology, ophthalmology, and otolaryngology were performed depending on the presence of surgeons with training in those subspecialties. Most of the operations $(18401,86.4 \%)$ were not complex and fell into groups A and B (table II). Table III lists the 10 most commonly performed major and minor operations. Most operations were carried out under general anaesthesia in the University Teaching Hospital and in other hospitals that had clinical officers who had trained in anaesthesia at the teaching hospital (table IV) whereas in three church hospitals (Luampa, Chitokoloki, and Chikankata) local or regional anaesthesia was given to over half of the patients. Table V gives the number of operations performed at each hospital in general surgery and they are grouped according to complexity-that is, A, B, C, D.

\section{Discussion}

This audit of operations carried out in district, church, and central hospitals in central Africa provides no information on urgent operations that were needed but not done or which elective operations might have been carried out if surgeons with adequate skills and adequate facilities had been available. Nordberg estimated that less than $15 \%$ of necessary operations are performed in east Africa. ${ }^{1}$

Nurses had recorded the operations in all the hospitals visited. Thus operations were not listed as accurately as if a surgeon had kept the records. For example, "laparotomy" covers many different procedures. This probably does not alter the overall picture, however. Operations performed under local anaesthesia in outpatient clinics-for example, pterygium and cystoscopy at the teaching hospital-were not included in the register.

In most teaching hospitals operations such as circumcision, hydrocelectomy, or orchidopexy would be performed by a urologist or by a general surgeon, and for this audit they were included under general surgery. Goodacre reported that $16-19 \%$ of the surgery performed in Mvumi Hospital in rural Tanzania was plastic or reconstructive surgery. ${ }^{3} \mathrm{He}$ included skin grafts for burns, drainage of hand infections, leg ulcers, and urogenital fistulas under plastic surgery. Most of these operations are also within the competence of the general surgeon who has no formal training in plastic surgery. We included more specialised operations such as cleft lip and palate repair under group D general surgery-that is, requiring subspecialty training. All operations in groups $A, B$, and $C$ should be within the capability of a general surgeon with an FRCS, an MMed(Surg), or an equivalent degree, who can treat at least $90 \%$ of surgical disorders. Surgeons who are being trained in urology and orthopaedics should first train in general surgery to be able to perform most surgery in groups A, B, and C. Most surgeons in Europe and in Africa are not trained broadly enough to meet the demands in rural Africa. ${ }^{4}$

We make the following recommendations:

(1) Doctors in district hospitals should be taught how to perform operations in groups A and B. Clinical officers can also be trained in countries where this is acceptable. Not all doctors would be expected to carry out all of these operations, but they would be able to perform commonly needed and lifesaving procedures.

(2) Doctors should be trained in hospitals where reasonable numbers of commonly needed operations can be performed in a short time. The central teaching hospital may not be the right place, for such training conflicts with the needs of the MMed programmes.

(3) A trained doctor should be supported in his hospital by

TABLE III-Ten most frequently performed major and minor operations. (All hospitals combined)

\begin{tabular}{ll|ll}
\hline Major operations & No & Minor operations & No \\
\hline Caesarean section & 917 & Dilatation and curettage (including & \\
Laparotomy (including ruptured & & 342 terminations) & 5401 \\
ectopic and turbo-ovarian surgery) & 696 & Abscess & 3418 \\
Hernia and scrotum & 475 & Closed reduction & 1642 \\
Sequestrectomy & 380 & Biopsy excision & 1551 \\
Operative reduction or internal fixation & 366 & Wound repair & 667 \\
Cataract & 340 & Foreign body removal & 591 \\
Amputation & 189 & Skin graft/sloughectomy & 572 \\
Hysterectomy & 183 & Cystoscopy & 517 \\
Trabeculectomy & 153 & Circumcision & 318 \\
Appendix & 116 & Perianal &
\end{tabular}

TABLE IV-Number of operations in which anaesthesia was used

\begin{tabular}{lcrrr}
\hline & & \multicolumn{3}{c}{ Anaesthesia } \\
\cline { 3 - 5 } & Total No of & \\
\cline { 3 - 5 } & operations & None & General & Local or spinal \\
\hline University Teaching Hospital & 15937 & 357 & 14483 & 1097 \\
Monze & 1793 & 27 & 1701 & 65 \\
Mongu & 1431 & 153 & 712 & 566 \\
Luampa & 403 & & 1 & 402 \\
Solwezi & 432 & 3 & 384 & 45 \\
Chikankata & 793 & 100 & 336 & 357 \\
Chitokoloki & 408 & & 71 & 337 \\
Luwingu & 95 & & 6 & 89 \\
\hline
\end{tabular}

Note: Figures were obtained from the operation register book in each hospital.

regular visits from a specialist surgeon who can gradually expand his repertoire and perform the more difficult procedures. The visit of the specialist helps to maintain morale and quality control and gives confidence to the doctors in district hospitals. Such visits are most economical if made by small plane. ${ }^{6}$ Mobile operating theatres may be driven to rural areas, where clinical assessment, surgery, and postoperative care may be carried out. ${ }^{78}$

(4) General surgeons should be trained to perform most, if not all, group A, B, and C operations and thus have to be more "generally" trained than surgeons in the West. They should receive part of their training in district hospitals. Postfellowship or higher surgical training should be taken in one of the subspecialties.

TABLE II-Numbers (and percentage underneath) of operations in each subspecialty from groups $A$ and $B$ (figures in parentheses are total numbers of operations performed)

\begin{tabular}{|c|c|c|c|c|c|c|}
\hline & General surgery & Urology & Orthopaedics & $\begin{array}{l}\text { Obstetrics and } \\
\text { gynaecology }\end{array}$ & $\begin{array}{l}\text { Ophthalmology and } \\
\text { ear, nose, and throat }\end{array}$ & Total \\
\hline University Teaching Hospital & $6447(7052)$ & $210(364)$ & $1772(2334)$ & $4730(5574)$ & $320(613)$ & 13479 \\
\hline Monze & $\begin{array}{c}(91 \cdot 4) \\
701(705) \\
(99 \cdot 4)\end{array}$ & $\begin{array}{c}(57 \cdot 6) \\
4(7) \\
(57 \cdot 1)\end{array}$ & $\begin{array}{c}(75.9) \\
183(190) \\
(96.3)\end{array}$ & $\begin{array}{c}(84 \cdot 8) \\
750(891) \\
(84 \cdot 2)\end{array}$ & $\begin{array}{c}(52 \cdot 2) \\
-\end{array}$ & $\begin{array}{c}(84 \cdot 5) \\
1638 \\
(91 \cdot 3)\end{array}$ \\
\hline Mongu & $\begin{array}{c}769(820) \\
(93 \cdot 7)\end{array}$ & $\begin{array}{l}43(51) \\
(84 \cdot 3)\end{array}$ & $203(241)$ & $\begin{array}{c}289(307) \\
(94 \cdot 4)\end{array}$ & $12 \overline{12}(12)$ & $\begin{array}{l}(91.3) \\
1316 \\
(91.9)\end{array}$ \\
\hline Luampa & $\begin{array}{c}239(255) \\
(93 \cdot 7)\end{array}$ & $\begin{array}{l}1(1) \\
(100)\end{array}$ & $\begin{array}{l}13(15) \\
(86 \cdot 7)\end{array}$ & $\begin{array}{c}33(46) \\
(71 \cdot 7)\end{array}$ & $\begin{array}{l}86(86) \\
(100)\end{array}$ & $\begin{array}{l}372 \\
(92 \cdot 3)\end{array}$ \\
\hline Solwezi & $\begin{array}{c}225(256) \\
(87 \cdot 9)\end{array}$ & $\begin{array}{l}13(20) \\
(65)\end{array}$ & $\begin{array}{l}58(66) \\
(87.8)\end{array}$ & $\begin{array}{c}85(90) \\
(94 \cdot 4)\end{array}$ & 二 & $\begin{array}{c}381 \\
(88 \cdot 2)\end{array}$ \\
\hline Chikankata & $\begin{array}{c}426(446) \\
(95 \cdot 5)\end{array}$ & $\begin{array}{l}3(3) \\
(100)\end{array}$ & $\begin{array}{c}36(48) \\
(75)\end{array}$ & $\begin{array}{c}226(228) \\
(99)\end{array}$ & $\begin{array}{l}71(71) \\
(100)\end{array}$ & $\begin{array}{l}762 \\
(96)\end{array}$ \\
\hline Chitikoloki & $\begin{array}{c}217(244) \\
(88.9)\end{array}$ & $\begin{array}{c}4(15) \\
(26.6)\end{array}$ & $\begin{array}{l}10(12) \\
(83 \cdot 3)\end{array}$ & $\begin{array}{l}97(107) \\
(90 \cdot 6)\end{array}$ & $\begin{array}{l}30(30) \\
(100)\end{array}$ & $\begin{array}{c}358 \\
(87 \cdot 7)\end{array}$ \\
\hline Luwingu & $\begin{array}{l}64(64) \\
(100)\end{array}$ & - & $\begin{array}{l}31(31) \\
(100)\end{array}$ & - & - & $(100)$ \\
\hline Total & $\begin{array}{c}9088(9842) \\
(92 \cdot 3)\end{array}$ & $\begin{array}{c}278(461) \\
(60 \cdot 3)\end{array}$ & $\begin{array}{c}2306(2937) \\
(78 \cdot 5)\end{array}$ & $\begin{array}{c}6210(7243) \\
(85 \cdot 7)\end{array}$ & $\begin{array}{c}519(812) \\
(63.9)\end{array}$ & $\begin{array}{l}18401 \\
(86 \cdot 4)\end{array}$ \\
\hline
\end{tabular}


The teaching hospitals in most developing countries are better equipped than other hospitals and have the highest concentration of specialists and subspecialists. They are also more expensive both for the state and for the family, who usually pay for transport to and
To achieve the worthy aim "surgery for all by the year 2000 ", responsibility for surgery cannot be confined to the surgeon with a conventional higher degree. General doctors must be taught and encouraged to perform surgery in district hospitals.

TABLE V-Number of operations carried out in general surgery grouped by complexity *

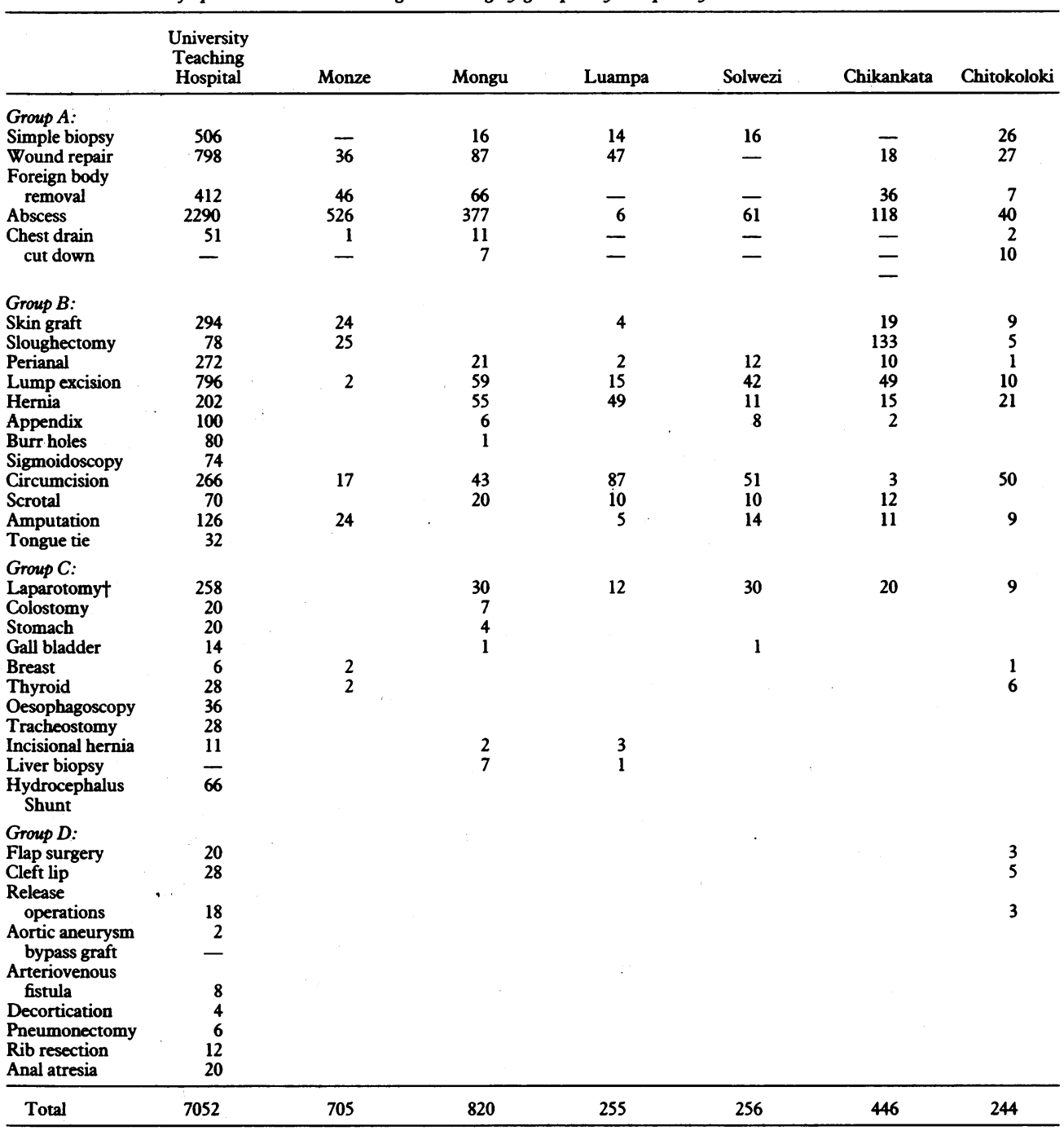

* Tables giving figures for operations in groups A-D for the subspecialties are available from the authors.

tIn Monze 73 laparotomies were classified under obstetrics and gynaecology because reason for laparotomy was not specified in operation register.

from the city, and it costs even more to transport a body home if a patient dies. Patients who require operations in groups A and B therefore need not be referred from the district hospital to the teaching hospital, which also diminishes the reputation of the district hospital. All large cities need one district hospital.

(5) Subspecialists should concentrate their time on group C and $\mathrm{D}$ operations, teaching surgical trainees, and supporting district hospital doctors.

(6) More use should be made of local, regional, and spinal anaesthesia, and these techniques should be taught to all district hospital doctors for use in most operations in groups A and B. Regional and spinal anaesthetic techniques are cheaper, more appropriate, and safe, provided they are carefully carried out.

(7) The district hospital doctor could be trained in two years as follows: three months' anaesthesia; six months' obstetrics and gynaecology; one year general surgery and orthopaedics; three months' option in urology, ophthalmology, or otolaryngology. This and two years of supervised experience in a district hospital should qualify the trainee for examination for a fellowship or master's degree in district hospital medicine.
We thank Ms R Spencer, Mr D Gaskell, and Drs A Watters, I Campbell, and J R Sinclair for providing some of the audit figures.

\section{References}

1 Nordberg EM. Incidence and estimated need of caesarean section, inguinal hernia repair, and operation for strangulated inguinal hernia in rural Africa. Br Med f 1984;289:92-3.

2 Gil AV, Galarza MT, Guerrero R, de Velez P, Peterson OL. Surgeons and operating rooms: underutilized resources. Am $\mathcal{F}$ Public Health 1983;73:1361-5.

3 Goodacre TE. Plastic surgery in a rural African hospital: spectrum and implications. Ann $R$ Coll Surg Engl 1986;68:42-4.

4 Carswell JW. Regional higher specialist training. Proceedings of the Association of Surgeons of East Africa 1986; 9 (suppl): 17-9.

5 Loefler IJP. Visits to outlying hospitals. Proceedings of the Association of Surgeons of East Africa (in press).

Fe. The Flyspec project. Proceedings of the Association of Surgeons of East Africa (in press). 7 Schwab L. Eye surgery for developing countries. Proceedings of the Association of Surgeons of East Africa (in press).

8 Hill JC. Mobile eye-care teams and rural ophthalmology in southern Africa. $S$ Afr Med $\mathcal{F}$ 1984;66:531-5.

9 Jellis JE, ed. Surgery in Africa in the year 2000. Proceedings of the Association of Surgeons of East Africa 1986;9(suppl): 1-71.

(Accepred 27 fuly 1987) 